\title{
Stop Bullying: Analisis Kesadaran dan Tindakan Preventif Guru pada Anak Pra Sekolah
}

\author{
Rita Mahriza $^{1} \bowtie$, Meutia Rahmah ${ }^{2}$, Nani Endri Santi ${ }^{3}$ \\ Pendidikan Islam Anak Usia Dini, Institusi Agama Islam Negeri Langsa \\ DOI: $\underline{10.31004 / \text { obsesi.v5i1.739 }}$
}

\begin{abstract}
Abstrak
Keberadaan sekolah menjadi tempat munculnya bibit-bibit penerus bangsa yang berperilaku menyimpang, melalui bullying. Tujuan penelitian ini adalah untuk mengamati bentuk perilaku bullying yang terjadi pada anak usia prasekolah dan mengelompokkan tindakan preventif guru terhadap perilaku bullying yang terjadi pada anak usia prasekolah. Metode penelitian yaitu pendekatan kualitatif. Teknik pengumpulan data berupa interview dan observasi. Hasil penelitian menunjukkan bahwa bentuk bullying yang dilakukan anak seperti; mengejek, mengolok-olok, memukul, mencubit, menendang, menginjak kaki, mendorong teman. Tindakan preventif guru bersifat tindakan rasionalitas instrumental, dengan bentuk melerai dan memisahkan anak yang sedang memukul/mengejek temannya, disertai dengan cara memisahkan tempat duduk antar siswa sehingga mereka tidak kembali ricuh. Tindakan bersifat rasional nilai, seperti guru menegur anak yang memukul, menendang, mengejek, mencubit, mendorong temannya. Kemudian guru menyuruh anak untuk meminta maaf kepada temannya. Selanjutnya tindakan bersifat tindakan afektif, di mana guru menghibur si anak saat temannya mendorong, mengejek, mencubit, mengolok-olok anak tersebut.
\end{abstract}

Kata Kunci: bullying; prasekolah; paud; perilaku; tindakan preventif.

\section{Abstract}

The existence of schools is a place for future seeds of the nation to behave deviantly through bullying. The purpose of this study was to observe the form of bullying behavior that occurs in preschool children and to classify teacher preventive actions against bullying behavior that occurs in preschool children. The research method is a qualitative approach. Data collection techniques in the form of interviews and observations. The results showed that the forms of bullying carried out by children such as; taunting, making fun of, hitting, pinching, kicking, stomping on feet, pushing friends. The teacher's preventive action is an act of instrumental rationality, in the form of breaking up and separating children who are hitting / taunting their friends, accompanied by separating seats between students so that they do not come back into chaos. Actions are value rational, such as the teacher reprimanding a child who hits, kicks, taunts, pinches, pushes his friend. Then the teacher told the child to apologize to his friend. Furthermore, the action is affective action, in which the teacher comforts the child when his friend pushes, taunts, pinches, makes fun of the child.

Keywords: bullying; preschools; ece; behavior; preventive action.

Copyright (c) 2020 Rita Mahriza, Meutia Rahmah, Nani Endri Santi

$\triangle$ Corresponding author:

Email Address : ritamahriza@gmail.com (Langsa, Aceh, Indonesia)

Received 30 August 2020, Accepted 8 September 2020, Published 11 September 2020 


\section{PENDAHULUAN}

Pendidikan dibutuhkan manusia, karena pendidikan merupakan proses manusia dari yang tidak tahu menjadi tahu. Selain itu, pendidikan proses untuk mengubah sikap dan perilaku seseorang untuk menjadi manusia lebih baik lagi (Hasanah, 2016). Adapun pendapat Inanna (2018) pendidikan upaya yang mempunyai plan dalam proses pembelajaran bagi manusia agar tumbuh dan berkembang menjadi manusia, sebagai berikut: mandiri, berilmu, kreatif, bertanggung jawab, berakhlak mulia. Selajan dengan pendapat Nurhasanah \& Dwiyama (2019) bahwa pendidikan yaitu proses pembelajaran aktif yang direcanakan untuk mengembangkan potensi manusia, melalui: spiritual agama, pengendalian diri, akhlak mulia, berilmu, bermasyarakat serta berbangsa dan Negara. Tujuan pendidikan ialah mempersiapkan anak didik supaya mampu beradaptasi dengan lingkungan sekitar atau berbagai kondisi sehingga anak mampu survive dimasa depannya (Garzia et al., 2019).

Menurut Sari \& Azwar (2018) pada kenyataannya tujuan pendidikan berbanding terbalik, keberadaan lembaga pendidikan yang seharusnya dijadikan tempat beradaptasi agar anak tumbuh dan berkembang baik, namun menjadi tempat munculnya bibit-bibit penerus bangsa yang berperilaku menyimpang salah satunya bullying. Sesuai dengan penelitian yang dilakukan oleh Nasir et al., (2019) ditemukan bahwa bullying terjadi diruang lingkup pendidikan yang dilakukan anak didik. Bullying yang terjadi karena belum adanya rasa solidaritas, kasih sayang, serta kebersamaan antar sesama teman. Menurut KPAI pengaduan masyarakat terhadap kasus bullying dari tahun 2011-2014 sekitar 25\% atau 1.480 kasus dari total pengaduan dalam bidang pendidikan (Setyawan, 2014).

Bullying merupakan bentuk perilaku kekerasan, biasanya target yang akan diganggu adalah anak-anak yang lemah. Hal ini selajan dengan pendapat (Zakiyah et al., 2017). Bullying ialah bentuk perilaku-perilaku kekerasan yang berupa pemaksanan secara psikologis dan fisik terhadap anak yang lebih lemah dari sekelompok orang yang kuat. Bullying merupakan aksi atau perilaku negatif yang bersifat agresif dan manipulatif, dilakukan satu orang bahkan lebih dalam kurung waktu tertentu, dengan cara kontak fisik langsung, kontak verbal langsung, perilaku non-verbal langsung, perilaku non-verbal tidak langsung, atau pelecehan seksual terhadap anak-anak yang lemah (Sucipto, 2012).

Adapun jenis-jenis bullying menurut Widianti (2019), yaitu: (1) Bullying Fisik, seperti: memukul, menendang, mecambuk, yang berhubungan dengan fisik. (2) Bullying Sosial memberikan impak yang tidak baik terhadap korban, seperti: mengucilkan, meremehkan, dihina. Sehingga membuat korban menjadi depresi, cemas, terisolir sosial dan rendah diri. (3) Bullying Verbal, berupa: fitnah, pencemaran nama baik, kekerasan verbal, menahan informasi, mengucilkan, mengabaikan pendapat, mengancam, mengejek. (4) Cyber Bullying, seperti: mengancam dan melecehkan seseorang via social media.

Menurut Prasetyo (2014) bullying terjadi karena beberapa faktor yaitu: (1) Ketidakseimbangan kekuatan pelaku dan korban. Dimana pelaku bullying memiliki kekuatan, sedangkan korban bullying lebih lemah. Ketidakseimbangan tersebut antara lain, ukuran badan, fisik yang kuat, mempunyai komunikasi yang bagus, status sosial, memiliki teman banyak, dan kekuasaan. Sedangkan korban bullying kebalikan dari pelaku bullying. (2) Penyalagunaan ketidakseimbangan kekuatan seperti, suka menganggu, menyerang secara berulang-ulang, suka mengucilkan. Hal ini disebabkan untuk memperlihatkan kepada orang bahwa ia kuat dan orang tunduk terhadapnya.

Terjadinya bullying di lembaga pendidikan atau sekolah ialah proses dinamika suatu kelompok yang masing-masing memiliki peran tersendiri. Adapun peran yang ada dikelompok, yaitu: pelaku bully, asisten bully, reinovocer, neutral, victim, dan outsider (Sari \& Azwar, 2018). Pelaku bully adalah anak yang dikategorikan sebagai pemimpin suatu kelompok yang aktif terlibat dalam bullying. Asisten bully adalah anak yang terlibat aktif dalam bullying, mereka cenderung mengikuti perintah pelaku bully. Reinvorcer ialah anak yang ada ketika kejadaian bullying, perannya adalah menyaksikan, menertawakan korban, terprovokasi dari pelaku, mengajak anak-anak lainnya untuk menonton. Outsider ialah anak- 
anak yang tahu kejadian bullying, tetapi tak berdaya hanya melihat, tidak bisa melakukan apaapa seolah tak perduli. Victim adalah anak yang menjadi korban bullying yang tidak berdaya untuk melawan, karena tidak mempunyai keberanian untuk melawan. Neutral ialah pihak yang tidak terlibat apapun dalam bullying.

Tidak hanya di sekolah, bullying bisa terjadi diberbagai tempat, seperti: rumah, pondok pesantren, kantor, tempat bermain, ataupun pendidikan anak usia dini (Sucipto, 2012). Bullying dapat muncul pada anak usia dini yang berusia 3 tahun yang terlibat dalam tindakan bullying (Ambarini et al., 2018). Namun, banyak guru tak menyadari bahwa anak usia dini bisa terlibat dalam tindakan bullying. Guru-guru menganggap bahwa perilaku yang anak lakukan adalah hal biasa dan tidak terpikir bahwa anak melakukan hal tersebut. Sejalan dengan Dey Putri et al., (2020) bahwa perilaku bullying tidak disadari oleh guru dan orang tua, karena menganggap bahwa anak-anak belum tahu mana yang baik dan benar sehingga merupakan hal yang wajar ketika anak berbuat negatif tersebut. Bullying yang dapat dilakukan anak usia dini, berupa: memukul, mencubit, mengejek, menendang, menarik rambut dan mencubit (Muthmainnah et al., n.d.). Berdasarkan penelitian Ronbanks di Skandinavia dalam (Sucipto, 2012) bahwa pelaku bullying yang dilakukan anak sekolah selama beberapa tahun, maka mereka menjadi pelaku kriminal saat dewasa. Sedangkan korban bullying mengalami gangguan psikis, seperti: tidak percaya diri, tidak nyaman, cemas, bahkan menyebabkan bunuh diri.

Fenomena kesadaran dan tindakan guru terhadap bullying anak prasekolah menarik untuk dikaji menggunakan kerangka pemikiran Max Weber tentang "tidakan sosial". Menurut Max Weber dalam Umanailo (2019) ialah suatu tindakan individu sepanjang tindakan tersebut mempunyai makna arti subjektif baik sendiri maupun orang lain. Konsep tindakan sosial sebagai alat analisis untuk mengetahui kesadaran guru serta tindakan terhadap bullying pada anak prasekolah. Sejalan dengan tersebut, penelitian ini akan menelusuri bagaimana kesadaran dan tindakan preventif guru terhadap bullying yang terjadi pada anak prasekolah.

Tindakan preventif guru sangatlah penting untuk mencegah terjadinya bullying pada anak usia dini (Alsaker \& Valkanover, 2012). Tindakan yang dapat dilakukan adalah menanamkan sejak dini kepada anak bahwa semua orang bersaudara dan saling menyayangi, memberikan nilai-nilai keagamaan terhadap anak agar anak berpikir untuk menyayangi sesama manusia dan tidak menyakiti. Selain itu pihak sekolah sebaiknya menciptakan lingkungan yang positif atau membuat RPP terkait pencegahan bullying.

Adapun penelitian yang dilakukan Purnama et al., (2018) tentang perilaku bullying pada anak di TK Aisyiyah Bustanul Athfal I Kota Makassar adalah terdapat perilaku bullying verbal yang dilakukan anak perempuan seperti mengejak. Sedangakan bullying fisik banyak dilakukan oleh anak laki-laki, seperti: memelintir tangan, menendang, melempar, memukul, mendang, dan lain-lain. Sedangkan penelitian Ambarini et al., (2018) tentang antisipasi pencegahan bullying sedini mungkin dengan membuat program anti bullying terintegrasi untuk anak usia dini. Sebagai tujuan agar guru dan staf PAUD dapat melaksanakan dan menerapkan program anti bullying sebagai pencegahan dan antisipasi di sekolah, sehingga mampu mengembangkan kemampuan sosial yang bersifat positif. Hasil penelitian yang didapatkan adalah guru-guru dapat menyiapkan RPP tentang bullying yang terjadi pada anak usia dini dan memggunakan story telling/bermain peran untuk mencegah bullying. Selain itu, bullying pada anak usia dini dapat dilakukan dengan tindakan preventif dari guru.

Keterbaruan dalam penelitian ini adalah tindakan preventif bagi guru dalam pencegahan bullying pada anak prasekolah dengan menggunakan "tindakan sosial" dari Max Weber. Tujuan dari penelitian ini adalah mengamati bentuk perilaku bullying yang terjadi pada anak usia prasekolah dan mengelompokkan tindakan preventif guru terhadap perilaku bullying yang terjadi pada anak usia prasekolah. Pencegahan bullying pada anak usia dini dangat penting untuk dideteksi oleh seorang guru, agar ke depannya anak tidak melakukan 
hal tersebut. Karena dampak dari perilaku bullying bagi korban adalah anak menjadi minder, ketakutan, menyendiri, bahkan lebih parah lagi menyebabkan bunuh diri.

\section{METODOLOGI}

Metode yang digunakan dalam penelitian ini dalah kualitatif. Lokasi penelitian adalah satuan pendidikan anak usia dini yang terdapat di Kota langsa yaitu TK Pembina Kota Langsa, RA Al Ashriyah, dan RA Marhamah. Adapun subjek pada penelitian ini adalah guru dan anak usia prasekolah 5-6 tahun. Teknik pengumpulan yang digunakan adalah observasi dan wawacara. Analisis data yang digunakan adalah analisis domain, analisis taksonomi, dan analisis komponensial.

Dalam penelitian ini peneliti merupakan salah satu instrumen kunci yang secara langsung mengamati, mewawancarai dan mengobservasi objek yang diteliti. Peneliti merupakan pengamat penuh yang akan mengamati potensi atau tindakan bullying yang terjadi pada usia prasekolah serta pengamatan tindakan guru terhadap potensi/perilaku bullying yang terjadi. Penelitian ini dilaksanakan selama 10 hari secara berturut-turut disetiap PAUD. Berikut ini gambar dari tahapan penelitian yang dilakukan.

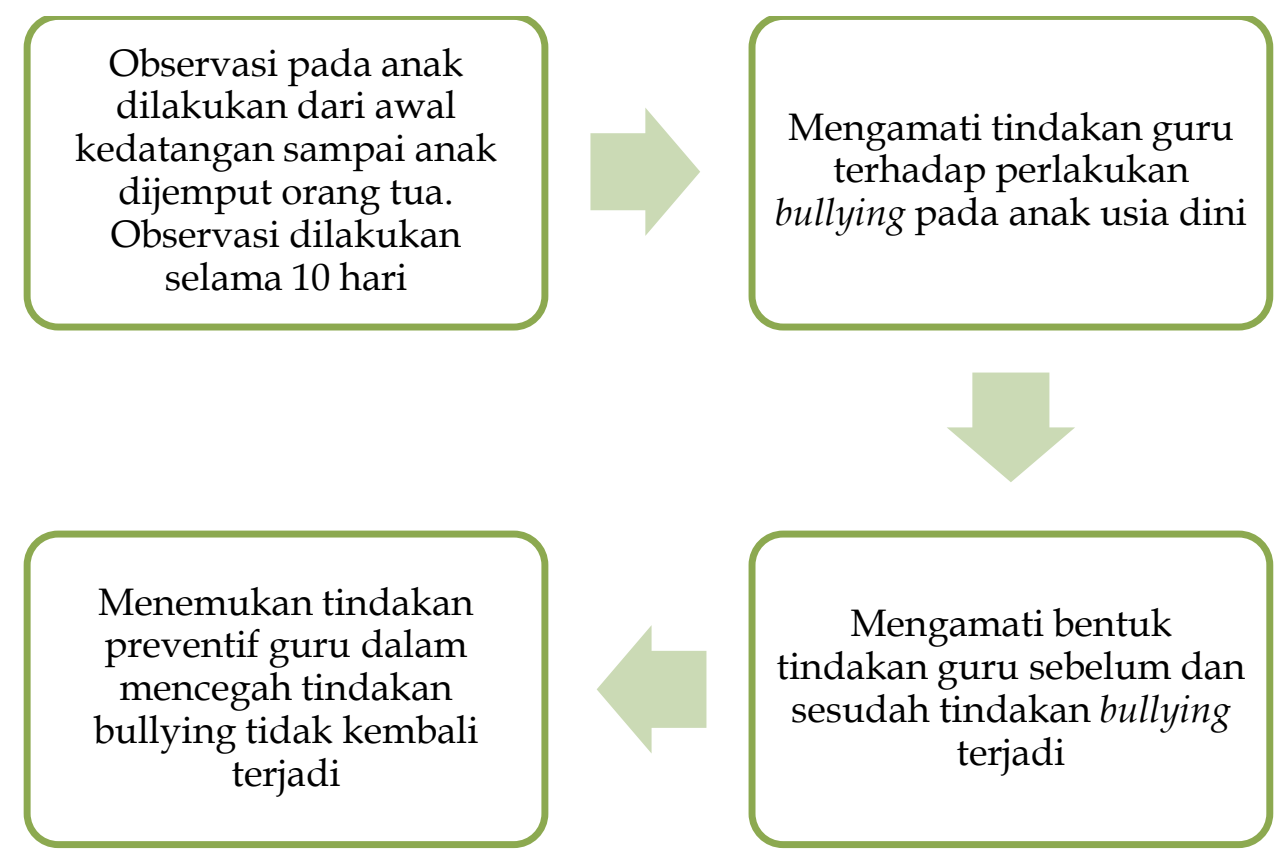

Gambar 1. Tahap Penelitian

\section{HASIL DAN PEMBAHASAN}

Hasil penelitian ditemukan bahwa sering terjadi tindakan bullying yang tanpa disadari oleh siswa itu sendiri maupun guru,walaupun tindakan bullying tersebut masih masuk dalam kategori ringan. Tindakan dari bullying tersebut bisa berbentuk bullying fisik, bullying psikis, dan bullying verbal.

PAUD Sample 1. Berdasarkan temuan kejadian yang didapat pasca observasi, diketahui bahwa telah terjadi banyak tindakan bullying pada satuan PAUD 1. Meskipum tidakan bully tersebut masih dapat dikategorikan dalam tundakan bullying tingkat rendah. Tingkat rendah yaitu bullying verbal, namun hal tersebut akan terus meningkat menjadi tindakan bullying yang lebih serius lagi.

Pada kejadian M mengganggu A dengan cara M mencolek A pada saat belajar melipat baju serta menarik - narik baju yang sudah dilipat A sehingga menjadi rusak, hal ini merupakan tindakan bully yang telah dilakukan oleh A. Dalam mensikapi kasus ini, Guru menegur $M$ sebagai peringatan awal agar berhenti mencolek dan mengganggu A serta 
meminta M untuk meminta maaf kepada A karena telah merusak hasil kerja A (Melipat baju). Pada kasus ini, tindakan guru dapat dikategorikan kepada tindakan rasional nilai, dan tindakan preventif telah dilakukan dengan cara menegur dan meminta murid untuk meminta maaf agar tindakan $\mathrm{M}$ tidak berlanjut menjadi lebih meningkat lagi.

Pada kasus selanjutnya, SQR sering mengganggu teman - temannya pada saat proses pembelajaran. Pada beberapa kasus yang ditemukan nama SQR selalu menjadi catatan misalkan saja pada hari kamis tanggal 29 Agustus 2019, SQR mencolek temannya hingga merasa terganggu. Pada lain hal, SQR memotong barisan antrian mencuci tangan sehingga terjadi tolak - menolak antar siswa dan ditindaklanjuti oleh guru dengan menertibkan SQR agar mengantri pada tempatnya, selanjutnya pada hari jumat tanggal 30 Agustus 2019, kembali SQR juga melakukan adu fisik kali ini dengan seorang siswa laki - laki yaitu AQ. Pada awalnya SQR dan AQ hanya bercengkrama, namun berakhir dengan berantam dikarenakan baik SQR suka memukul dan AQ suka menendang, pada peristiwa ini, tindakan guru adalah melerai keduanya serta memberikan nasihat serta pengertian bahwa apa yang mereka lakukan adalah hal yg salah. Masih dengan siswa yang sama, yaitu SQR, kembali melakukan kesalahan dengan menuduh temannya QR menolaknya sehingga terjatuh dari ayunan. Dalam kejadian ini guru kembali melakukan tindakan dengan cara mencari tahu kebenaran dan meminta SQR meminta maaf kepada QR setelah memastikan bahwa QR tidak melakukan penolakan seperti yang dituduhkan oleh SQR.

Dalam peristiwa yang terjadi pada hari Sabtu tanggal 31 Agustus 2019, seorang siswa, $\mathrm{QR}$, lupa membawa bekal sehingga marah - marah dan mengamuk. Tindakan yang dilakukan guru adalah dengan menenangkan $\mathrm{QR}$ dan mengajarkan siswa yang lain untuk berbagi terhadap teman yang sedang kesusahan. Pada saat makan, QR mengganggu teman - teman lain yang sedang makan dan menggertak teman - teman lain yang mengasihaninya, bahkan QR juga mendorong piring berisi kue pemberian dari teman - temannya. Dalam hal ini, tindakan yang dilakukan guru adalah dengan menegur QR dan menghibur teman - teman yang sedih karena merasa tidak dihargai pemberiannya oleh QR. Namun karena QR juga tetap tidak berhenti, guru menegur dan mengatakan akan memulangkan $Q R$ jika ia masih mengganggu teman - temannya.

Masa usia dini adalah masa dimana anak gemar bermain, namun bermain mereka dapat membahayakan jika tidak diawasi oleh guru. Sebagai contoh bermain timpah - timpah badan yang dilakukan oleh $\mathrm{AB}, \mathrm{AR}$, dan $\mathrm{AD}$ pada awalnya adalah bermain namun ketika seseorang merasa tersakiti, dua teman yang lain tetap tidak menghentikan. Peristiwa tersebut sudah sering terjadi namun masih saja dilakukan oleh siswa. Dalam hal ini, guru memisahkan posisi duduk mereka dan memberi nasihat. Pada hari yang lain, kembali peristiwa serupa terjadi yang dilakukan oleh HS dan ND, dalam hal ini tindakan yang dilakukan guru adalah dengan menegur HS dan ND serta memberikan pengertian kepada seluruh murid bahwa kejadian tersebut sangat membahayakan anak - anak dan memiliki resiko patah tulang belakang. Sehingga untuk beberapa hari kedepan tidak ada kejadian serupa terjadi kembali.

Dari beberapa peristiwa pada satuan PAUD sample 1 diatas, pada hakikatnya masih banyak lagi peristiwa serupa yang terjadi. Tentu saja ini merupakan kasus bullying yang masih dapat dikategorikan pada tingkat rendah dan berpotensi untuk meningkat menjadi bully pada kategorei sedang dan berat jika terus dibiarkan dan tidak ditindaklanjuti. Satuan PAUD sudah melakukan tindakan yang benar dengan melakukan tindakan pencegahan bully berupa menegur, memberi nasihat, menyuruh untuk meminta maaf, bahkan dengan pengancaman sederhana yang dapat dikategorikan pada tindakan sosial pada kategori tindakan Rasionalitas instrumental, Rasional Nilai, dan Tindakan afektif sesuai dengan teori yang digambarkan oleh Max weber. Berikut ini tabel bullying di paud dan tindakan preventif dari guru: 


\section{Tabel 1. Bullying di PAUD Sampel 1 dan Tindakan Preventif Guru}

\begin{tabular}{|c|c|c|c|}
\hline No & Kasus Bullying & Akibat & Tindakan Preventif \\
\hline 1 & $\begin{array}{l}\text { Kasus I : Mengganggu } \\
\text { dengan cara mencolek } \\
\text { teman, sehingga pekerjaan } \\
\text { temannya menjadi rusak. }\end{array}$ & $\begin{array}{l}\text { Anak } \\
\text { menangis }\end{array}$ & $\begin{array}{l}\text { 1. Melakukan Tindakan rasional nilai dalam } \\
\text { mencegah bullying dengan cara menegur dan } \\
\text { meminta anak untuk meminta maaf agar } \\
\text { tidak terulang kembali. }\end{array}$ \\
\hline 2 & $\begin{array}{l}\text { Kasus II : menganggu, } \\
\text { mencolek teman, tidak } \\
\text { mengantri hingga terjadi } \\
\text { tolak-menolak antar anak } \\
\text { lainnya, berkelahi, memukul, } \\
\text { menendang, dan menuduh } \\
\text { temannya. }\end{array}$ & $\begin{array}{l}\text { Anak } \\
\text { menangis }\end{array}$ & $\begin{array}{l}\text { 1. Melakukan tindakan rasional nilai, seperti: } \\
\text { mentertibkan agar anak mengantri, } \\
\text { mengucapkan maaf. } \\
\text { 2. Tindakan rasional instrumental, seperti: } \\
\text { melerai dan memberi nasihat anak yang } \\
\text { bekelahi, mencari kebenaran dalam menuduh }\end{array}$ \\
\hline 3 & $\begin{array}{l}\text { Kasus III : terdapat anak yang } \\
\text { marah-marah, menganggu, } \\
\text { menggertak teman-teman }\end{array}$ & $\begin{array}{l}\text { Anak } \\
\text { menangis }\end{array}$ & $\begin{array}{l}\text { 1. Tindakan rasional nilai : meminta anak } \\
\text { mengucapkan maaf } \\
\text { 2. Tindakan Afektif : Menghibur anak yang } \\
\text { sedih }\end{array}$ \\
\hline 4 & $\begin{array}{l}\text { Kasus IV : menyakiti } \\
\text { temannya ketika bermain }\end{array}$ & $\begin{array}{l}\text { Anak } \\
\text { menangis }\end{array}$ & $\begin{array}{l}\text { 1. Tindakan Rasional Instrumental dan rasional } \\
\text { nilai: dengan memberikan } \\
\text { pengertian/nasihat utuk menghentikan } \\
\text { permainan yang membuat anak lain } \\
\text { kesakitan }\end{array}$ \\
\hline
\end{tabular}

Satuan PAUD Sample 2. Pada satuan PAUD sample 2, terjadi beberapa kasus bully pada kategori tingkat ringan seperti mengejek, mendorong, melempar mainan, dan mencubit. Namun pada Satuan PAUD Sample 2 ini terjadi beberapa bully pada kategori tingkat sedang yaitu bullying fisik, berupa: memutar tangan, menampar, menggigit tangan hingga berbekas, menjepit tangan dan kaki, bahkan menumpahkan sisa makanan keatas kepala kawan.

Dalam peristiwa bully yang terjadi pada satuan PAUD sample 2, telah dilakukan pengawasan dan tindakan oleh guru. Misalkan saja pada kasus yang terjadi pada tanggal 3 September tahun 2019, ketika IJ mengejek RK karena tidak mendapakan bintang dari ibu guru, maka ibu guru memberikan nasihat agar tidak mengejek dan memberikan pengertian untuk saling menyayangi teman. Selanjutnya masih dihari yang sama, pada peristiwa AF mengejek NY dengan perkataan NY paling jelek dikelas, tindakan guru yang dilakukan juga dengan menasihat AF agar tidak mengejek kembali. Selanjutnya pada kasus IK memukul HF, kembali tindakan yang dilakukan oleh guru adalah dengan memberikan pengertian untuk saling menyayangi teman dan minta IK untuk meminta maaf. Masih dalam hari yang sama, IK memukul HF didalam kelas tindakan guru yang dilakukan adalah memberi pengertian kepada IK agar tidak menyakiti teman dan meminta IK untuk meminta maaf kepada HF.

Pada peristiwa bully tingkat sedang yang terjadi pada satuan sample 2, yaitu memutar tangan, menampar, menggigit tangan hingga berbekas, menjepit tangan dan kaki, bahkan menumpahkan sisa makanan keatas kepala kawan, tindakan yang dilakukan oleh guru adalah dengan memberikan kasih sayang kepada siswa yang disakiti oleh temannya serta memberikan nasihat utuk saling menyayangi dan meminta siswa yang melakukan bully untuk meminta maaf kepada temannya.

Dari beberapa peristiwa pada satuan PAUD sample 2 diatas, pada hakikatnya masih banyak lagi peristiwa serupa yang terjadi, bahkan beberapa kasus cenderung mengarah kepada tingkat sedang. Dalam hal ini, tentu saja bully tersebut berpotensi untuk meningkat menjadi bully pada kategori yang lebih tinggi, yaitu sedang dan berat jika terus dibiarkan dan tidak ditindaklanjuti. Satuan PAUD sample 2 sudah melakukan tindakan yang benar dengan melakukan tindakan pencegahan bully berupa menegur, memberi nasihat, menyuruh untuk meminta maaf, dan memberikan pengertian agar selalu menyayangi sesama teman. Tindakan yang dilakukan oleh satuan PAUd sample 2 ini lebih cenderung pada tindakan sosial dalam bentuk tindakan Afektif, namun tindakan Rasionalitas instrumental dan Rasional Nilai sesuai 
dengan teori yang digambarkan oleh Max weber. Berikut ini tabel bullying di paud dan tindakan preventif dari guru:

Tabel 2. Bullying di PAUD Sampel II dan Tindakan Preventif Guru

\begin{tabular}{|c|c|c|c|}
\hline No & Kasus Bullying & Akibat & Tindakan Preventif \\
\hline 1 & $\begin{array}{l}\text { Kasus I : mengejek teman dan } \\
\text { memukul teman }\end{array}$ & $\begin{array}{l}\text { Korban } \\
\text { bullying } \\
\text { menangis }\end{array}$ & $\begin{array}{l}\text { 1. Tindakan Rasional nilai : menegur, } \\
\text { memberikan pengertian/nasihat } \\
\text { 2. Tindakan Rasional Instrumental : } \\
\text { meleraikan dan memisahkan saat anak } \\
\text { memukul }\end{array}$ \\
\hline 2 & $\begin{array}{l}\text { Kasus II : Pada peristiwa bully } \\
\text { tingkat sedang yang terjadi, } \\
\text { yaitu; memutar tangan, } \\
\text { menampar, menggigit tangan } \\
\text { hingga berbekas, menjepit } \\
\text { tangan dan kaki, bahkan } \\
\text { menumpahkan sisa makanan } \\
\text { keatas kepala kawan }\end{array}$ & $\begin{array}{l}\text { Menangis, } \\
\text { terdapat } \\
\text { luka dan } \\
\text { bekas } \\
\text { pukulan }\end{array}$ & $\begin{array}{l}\text { 1. Tindakan Rasional Instrumental : } \\
\text { meleraikan anak } \\
\text { 2. Tindakan rasional nilai: guru menegur } \\
\text { untuk meminta maaf, serta menasihati } \\
\text { anak yang menyakiti temannya. } \\
\text { 3. Tindakan Afektif: memberikan kasih } \\
\text { sayang kepada anak yang menjadi korban } \\
\text { bullying }\end{array}$ \\
\hline
\end{tabular}

Satuan PAUD Sample 3. Pada Satuan PAUD sample 3, juga ditemukan beberapa kasus bully dan masih pada kategori tingkat ringan. seperti menarik kaki, memukul, mengganggu teman, menarik dan menginjak baju, dan menarik sepatu.

Dari peristiwa yang terjadi, tindakan yang dilakukan guru adalah dengan meminta siswa yang melakukan kesalahan untuk meminta maaf kepada temannya dan memberikan nasihat agar tidak mengulangi kembali perbuatannya. Untuk memastikan apakah anak mengulangi lagi atau tidak, guru selalu mengamati anak-anak yang menjadi pelaku tersebut terhadap teman yang menjadi korban bully.

Pada kasus tindakan bully kategori ringan disatuan PAUD sample 3 di atas, pada hakikatnya sering terjadi peristiwa serupa. Tentu saja ini merupakan kasus bullying yang masih dapat dikategorikan pada tingkat rendah namun berpotensi untuk meningkat menjadi bully pada kategori sedang dan berat jika terus dibiarkan dan tidak ditindaklanjuti. Satuan PAUD sudah melakukan tindakan yang benar dengan melakukan tindakan pencegahan bully berupa menegur, memberi nasihat, menyuruh untuk meminta maaf dan tindakan sosial tersebut dapat dikategorikan pada tindakan Rasionalitas instrumental, Rasional Nilai, dan Tindakan afektif sesuai dengan teori yang digambarkan oleh Max weber.

Dari kasus - kasus bully yang terjadi pada ketiga sample diatas, pada hakikatnya sering dilakukan oleh siswa yang sama, misalkan saja pada Satuan PAUD sample A oleh SQR, pada satuan PAUD sample 2 oleh IJ, dan pada satuan PAUD sample 3 oleh AF. Para siswa ini akan memiliki potensi yang lebih dominan untuk menjadi pelaku Bully jika tidak segera ditindak lanjuti dan mendapat pengawasan yang intensif dari guru. Baik dari tindakan guru pada ketiga satuan PAUD tersebut telah melakukan tindakan yang baik terbukti dengan perbuatan siswa yang tidak konstan atau berkelanjutan misalnya seorang siswa melakukan bully selama 2 hari berturut namun dengan adanya pencegahan dan nasihat serta memberi pengertian maka bully akan berhenti dan akan kembali muncul beberapa hari setelahnya. Hal ini merupakan hal yang wajar dikarenakan sifat anak usia dini yang selalu harus diberikan pengertian dan pengawasan secara intensif.

Selanjutnya, dari ketiga sampel satuan PAUD diatas ditemukan bahwa tindakan guru pada tindakan rasional nilai dan tindakan afektif hanya berimbas ringan terhadap pelaku bully meskipun hal tersebut berdampak namun hanya sementara. Hal tersebut akan lebih memiliki imbas yang besar jika guru memberikan tindakan rasional instrumental. Dari peristiwaperistiwa yang telah terjadi pada ketiga satuan PAUD di atas, guru yang memberikan tindakan peneguran secara tegas akan lebih memiliki dampak lebih besar pada pelaku bully daripada tindakan guru dengan memberikan nasehat dan pengertian saja tanpa diiringi 
dengan tindakan rasional instrumental. Berikut ini tabel dari tindakan guru ketika mendapatkan anak yang melakukan bullying.

Bullying diartikan sebagai tindakan agresi yang dilakukan seseorang terhadap orang lain. Pentingnya guru mengidentifikasi anak-anak yang mendekati bullying, karena pada usia dini kemampuan sosial anak sedang berkembang, dan hal ini berkaitan juga dengan emosi anak. Jika kemampuan social dan emosi anak tidak seimbang, maka terbentuklah korban dan pelaku bullying (Mills, 2013). Dari hasil penelitian yang ditemukan bahwa bullying yang terjadi pada anak usia dini adalah mengejek, memukul, menendang, menampar, menggigit tangan, menjepit tangan dan kaki, menumpahkan makanan di kepala temannya, marah-marah, menganggu teman, menyakiti teman ketika bermain, menggertak, mendendang, dan menuduh. Adapun tidakan preventif yang dilakukan guru adalah tindakan rasional instrumental, tindakan rasional nilai dan tindakan efektif.

Hal ini sejalan dengan hasil penelitian Purnama et al., (2018) bahwa kasus bullying yang terjadi pada anak Taman Kanak-kanak di Kota Makassar adalah bullying non verbal atau fisik, seperti: merampas, memukul, menendang, mendorong, merusak, memelintir tangan, melempar. Biasanya bullying fisik banyak dilakukan oleh anak laki-laki. Sedangkan bullying verbal, seperti: mengancam dan mengejek dilakukan oleh sesama anak perempuan. Menurut Reunamo et al., (2015) banyak penelitian terbaru menunjukkan bahwa perilaku bullying terjadi dalam pendidikan anak usia dini yang berusia 3-7 tahun. Bullying merupakan faktor yang sangat beresiko untuk kehidupan anak selanjutnya, karena dapat membuat korban menjadi depresi, pengucilan social, bahkan lebih parahnya lagi bunuh diri (Jansen et al., 2012). Untuk itu, tindakan dari para pendidik sangatlah penting untuk mencegah bullying sejak dini.

Adapun program-program anti bullying yang dapat dilakukan guru dalam penelitian Ambarini et al., (2018) adalah bentuk kegiatan pelatihan, workshop dna pendampingan lapangan. Pada tahap I merupakan tahap penyampain materi-materi mengenai bullying. Tahap II adalah tahap pelatihan, seperti: membuat RPP tentang bullying. Tahap III adalah tahap praktik, pada tahap ini guru melakukan praktek pembelajaran mengenai bullying dalam bentuk peer teaching. Tahap IV adalah tahap praktik classroom practice berupa praktik pembelajaran bullying dengan rekan kelompok. Tahap V adalah tahap diskusi dan refleksi diri mengenai pembelajaran anti bullying.

\section{SIMPULAN}

Bibit bullying sudah terlihat pada anak usia dini. Namun, kebanyakan orang dewasa tidak tahu bahwa perbuatan tersebut adalah bentuk dari bullying. Bullying yang terjadi pada anak usia dini berupa bullying verbal dan bullying fisik. Bullying verbal pada anak usia dini, berupa: menjulurkan lidah, mengolok, mengejek, mengucilkan anak lain, menceritakan hal yang tidak baik, berkata kasar kepada teman. Perilaku bullying fisik anak usia dini, berupa: mencubit, memukul, menendang, menarik rambut, menampar, meninjak kaki, dan mendorong temannya. Tindakan preventif yang dilakukan oleh guru terhadap bullying adalah mengamati setiap kegiatan yang dilakukan anak dan tindakan social, seperti: resional instrumental, rasional nilai, dan afektif.

\section{UCAPAN TERIMA KASIH}

Terima kasih peneliti ucapkan kepada pihak-pihak terlibat dalam penelitian ini khususnya TK Pembina Kota Langsa, RA Al Ashriyah, RA Marhamah Kota Langsa, dan IAIN Langsa yang memberikan kesempatan dalam melakukan penelitian ini.

\section{DAFTAR PUSTAKA}

Alsaker, F. D., \& Valkanover, S. (2012). The Bernese Program against Victimization in Kindergarten and Elementary School. New Directions for Youth Development, 2012(133), 15-28. https://doi.org/10.1002/yd.20004 
Ambarini, R., Indrariani, E., \& Zahraini, A. (2018). Antisipasi Pencegahan Bullying Sedini Mungkin: Program Anti Bullying Terintegrasi Untuk Anak Usia Dini. Journal of Dedicators Community, 2(2), 64-82. https://doi.org/10.34001/jdc.v2i2.587

Dey Putri, L. A., Yetti, E., \& Hartati, S. (2020). Pengaruh Keterlibatan Orangtua dan Regulasi Diri terhadap Perilaku Bullying Anak Usia Dini. Jurnal Obsesi : Jurnal Pendidikan Anak Usia Dini, 4(2), 715. https://doi.org/10.31004/obsesi.v4i2.438

Garzia, M., Yufiarti, Y., \& Hartati, S. (2019). Perbedaan Kesiapan Sekolah Anak Usia Dini di Daerah Pesisir Ditinjau dari Status Ekonomi Orang Tua dan Parenting. Jurnal Obsesi : Jurnal Pendidikan Anak Usia Dini, 3(2), 470-483. https://doi.org/10.31004/obsesi.v3i2.239

Hasanah, U. (2016). Pengembangan Kemampuan Fisik Motorik Melalui Permainan Tradisional Bagi Anak Usia Dini. Jurnal Pendidikan Anak, 5(1), 717-733. https://doi.org/10.21831/jpa.v5i1.12368

Inanna, I. (2018). Peran Pendidikan dalam Membangun Karakter Bangsa yang Bermoral. JEKPEND: Jurnal Ekonomi Dan Pendidikan, 1(1), 27. https:// doi.org/10.26858/jekpend.v1i1.5057

Jansen, P. W., Verlinden, M., Berkel, A. D., Mieloo, C., van der Ende, J., Veenstra, R., Verhulst, F. C., Jansen, W., \& Tiemeier, H. (2012). Prevalence of bullying and victimization among children in early elementary school: Do family and school neighbourhood socioeconomic status matter? BMC Public Health, 12(1), 494. https://doi.org/10.1186/1471-2458-12-494

Mills, H. (2013). Bullying and the early childhood classroom. 36(4), 2009-2011.

Muthmainnah, Astuti, B., \& Fatimaningrum, A. S. (n.d.). Pelatihan Penanganan Bullying Pada Anak TK. 467-477.

Nasir, N., Rahmawati, R., \& Adam, A. (2019). Identifikasi Nilai Pedagogis Tarian Lulo untuk Memperkuat Rasa Persatuan pada Anak Usia Dini. Jurnal Obsesi : Jurnal Pendidikan Anak Usia Dini, 4(1), 371. https:// doi.org/10.31004/obsesi.v4i1.336

Nurhasanah, \& Dwiyama, F. (2019). Pengembangan Lembaga PAUD Melalui Implementasi Manajemen Berbasis Sekolah. Adaara: Jurnal Manajemen Pendidikan Islam, 8(1), 797-815. https://doi.org/10.35673/ajmpi.v8i1.419

Prasetyo, A. B. E. (2014). Bullying di Sekolah dan Dampaknya bagi Masa Depan Anak. ElTarbawi, 4(1), 19-26. https:/ / doi.org/10.20885/tarbawi.vol4.iss1.art2

Purnama, F., Herman, H., \& Saodi, S. (2018). Perilaku Bullying Pada Anak Di Taman KanakKanak Aisyiyah Bustanul Athfal I Cabang Bara-Baraya Kota Makassar. Publikasi Pendidikan, 8(1), 41. https:// doi.org/10.26858/publikan.v8i1.4480

Reunamo, J., Kalliomaa, M., Repo, L., Salminen, E., Lee, H.-C., \& Wang, L.-C. (2015). Children's strategies in addressing bullying situations in day care and preschool. Early Child Development and Care, 185(6), 952-967. https:// doi.org/10.1080/03004430.2014.973871

Sari, Y. P., \& Azwar, W. (2018). Fenomena Bullying Siswa: Studi Tentang Motif Perilaku Bullying Siswa di SMP Negeri 01 Painan, Sumatera Barat. Ijtimaiyya: Jurnal Pengembangan Masyarakat Islam, 10(2), 333-367. https://doi.org/10.24042/ijpmi.v10i2.2366

Setyawan, D. (2014). KPAI: Kasus Bullying dan Pendidikan Karakter. KPAI. https://www.kpai.go.id/berita/kpai-kasus-bullying-dan-pendidikan-karakter

Sucipto. (2012). Bullying Dan Upaya Meminimalisasikannya Bullying and Efforts To Minimize. Psikopedagogia, 1(1).

Umanailo, M. C. B. (2019). Max Weber. October. https://doi.org/10.31219/osf.io/ep7bn

Widianti, W. (2019). Mengenal Perilaku Bullying di Sekolah. Islamic Counseling: Jurnal Bimbingan Konseling Islam, 3(1), 55. https:/ / doi.org/10.29240/jbk.v3i1.801

Zakiyah, E. Z., Humaedi, S., \& Santoso, M. B. (2017). Faktor yang Mempengaruhi Remaja dalam Melakukan Bullying. Prosiding Penelitian Dan Pengabdian Kepada Masyarakat, 4(2), 324-330. https:// doi.org/10.24198/jppm.v4i2.14352 